
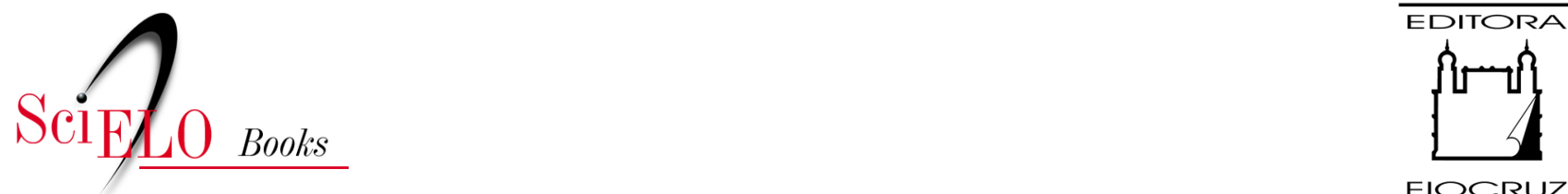

FIOCRUZ

\title{
1. Gênese e constituição da educação alimentar
}

\author{
Eronides da Silva Lima
}

\section{SciELO Books / SciELO Livros / SciELO Libros}

LIMA, E.S. Gênese e constituição da educação alimentar. In: Mal de Fome e não de raça: gênese, constituição e ação política da educação alimentar. Brasil, 1934-1946 [online]. Rio de Janeiro: Editora FIOCRUZ, 2000, pp. 27-43. ISBN: 978-85-7541-611-2. Available from: doi:

10.7476/9788575416112.0004. Also available in ePUB from:

http://books.scielo.org/id/xxmyz/epub/lima-9788575416112.epub.

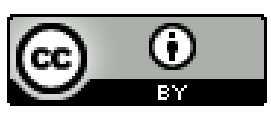

All the contents of this work, except where otherwise noted, is licensed under a Creative Commons Attribution $\underline{4.0 \text { International license. }}$

Todo o conteúdo deste trabalho, exceto quando houver ressalva, é publicado sob a licença $\underline{\text { Creative Commons }}$ Atribição 4.0. 


\section{GÊNESE E COÑSTITUIÇÃO DA EDUCAÇÃO ALIMENTAR}

É freqüente, na literatura, o debate entre a sociologia, a história e a filosofia sobre qual dos campos detém a primazia para desvendar os aspectos cognitivos e não-cognitivos da ciência, a saber: as imbricações entre conhecimento e verdade, as condiçóes históricas e o desenvolvimento da ciência moderna, as diferenças no seu desenvolvimento em sociedades distintas, os efeitos das instituições econômicas e políticas e do sistema de classe na organização do trabalho científico, as influências da definição do papel do cientista na estrutura e formação das comunidades científicas, a identidade do pesquisador e seu objeto, enfim, aspectos que refletem a necessidade da crítica interna $e$ externa na objetivação do saber.

Mannheim (1972), ao deslocar o indivíduo, como ser autônomo, para o âmbito do grupo social, deu um primeiro passo decisivo para a configuração da sociologia do conhecimento. A objetividade do conhecimento pode ser obtida nas ciências sociais, não por meio da exclusão das valorações, mas, sim, mediante a percepção e da crítica destas, em uma situação social específica. Nessa visão, o conhecimento não é um ato isolado e abstrato, mas contextualizado como processo determinado por valores e impulsos de um inconsciente coletivo. Numa sociedade caracterizada pela divisão do trabalho, pela extrema heterogeneidade e pelos conflitos de interesses, as imagens mentais que os indivíduos dela fazem tendem a ser opacas e incongruentes. $O$ inconsciente coletivo $e$ a atividade por ele exercida expressam, assim, um modo de ocultação, tanto no plano ideológico quanto no utópico, de certos aspectos da realidade social. É possível, no entanto, detectar precisamente as origens e a direção dessa distorção, a ponto de corrigi-las e recompor o equilibrio gerador da integração social, uma vez que:

Em cada sociedade, há grupos sociais cuja tarefa específica consiste em dotar aquela sociedade de uma interpretação do mundo. Chamamos tais grupos intelligentsia (...). Do ponto de vista sociológico, o fato decisivo dos tempos 
modernos, em contraste com a situação vigente na Idade Média, é o de ter sido quebrado este monopólio da interpretação eclesiástica do mundo, mantido pela casta sacerdotal, tendo surgido, no lugar de um estrato de intelectuais fechado e inteiramente organizado, uma intelligentsia livre. Sua característica principal é a de ser recrutada, de modo cada vez mais freqüente, em estratos e situações de vida constantemente variáveis, e de seu modo de pensamento não mais estar sujeito a ser regulado por uma organização tipo casta. (Mannheim, 1972:38-39) ${ }^{3}$

Sob essa perspectiva, é possível operar o estudo da gênese e a constituição da educação alimentar, privilegiando dois aspectos:

- as variações de interesses e da atuação dos intelectuais envolvidos com a produção do conhecimento instaurador desse campo nas mudanças ocorridas na estrutura social brasileira, de modo a verificar como esses interesses e os propósitos de determinados grupos sociais teriam encontrado expressão nessa modalidade de conhecimento;

- o modo pelo qual as próprias abordagens e métodos explicativos foram influenciados pela participação dos intelectuais nessa sociedade.

Na interface do postulado da utilidade, necessidade e controle, esse modo de reconstrução da história social da gênese e constituição da educação alimentar buscaria a compreensão desse processo, não como ato isolado, mas situado numa rede de relações sociais em interação, de onde teriam surgido os vários modos de conhecer as realidades existentes à época da sua produção. Nesse método, o significado adquire expressão como um veículo de precisão que permite inquirir o que esteve opaco no conhecimento assim construído.

A reinstauração do conceito de processo ideológico no estudo em foco, ao inquirir o que esteve opaco na produção para que se explicitem os pontos parciais e deformantes do conhecimento produzido, à luz de condições e interesses sociais determinantes do processo intelectual, ofuscaria o movimento dialético peculiar a essa atividade, privilegiando a priori códigos de pensamento produzidos numa seqüência linear e uniforme, recortando trechos das obras dos intelectuais instituidores da educação alimentar, de modo a indicar seus usos e significados, o que certamente reduziria o espaço de clarificação do caminho percorrido, pois, como afirma Schaff (1995:176):

Com efeito, se não se pressupõe ex definitione que a palaura 'ideologia' define as opiniões que, por causa dos interesses de classe, deformam a imagem da sociedade, nada impede, mesmo se admitindo sem reservas o

3 Para maior detalhamento do pensamento mannheimiano, ver: FoRACCHI (1982); SCHAFF (1995:141-185). 
condicionamento de classe das opiniōes dos homens sobre a realidade social, que as ideologias sejam não deformantes, mas adequadas, bem como científicas, qual est explicandum.

Segundo Ben-David (1975), o trabalho contemporâneo realizado pela sociologia da ciência se afastou das características do seu momento fundador, abandonando explicações sociológicas de conceitos e teorias da ciência, concentrando-se na explicação da própria atividade científica e de sua organização, e na crescente ênfase sobre o ponto de vista comparativo e do estudo intencional de grupos científicos, disciplinas e comunidades científicas, em acréscimo à visão institucional da década de 30. Morel (1979) assinala que, embora o autor tenha-se proposto a fazer uma análise sociológica da evolução da atividade científica, limitou seu estudo a uma análise historicista, estabelecendo analogias temporais entre o surgimento da ciência e o aparecimento do papel científico, explicando-o em termos de motivações pessoais de uma comunidade científica emergente, sem alcançar o cerne de tais motivações. Assim, mesmo procurando analisar a evolução da atividade científica, Ben-David parece não ter-se orientado pela história.

Para Chalmers (1994), há distinção entre os aspectos cognitivos e não-cognitivos da ciência no horizonte dos debates entre campos que disputam o domínio da crítica interna e externa na objetivação do conhecimento. Segundo ele, isso pode ser focalizado nas abordagens dos sociólogos contemporâneos, a exemplo de Bloor (1982) e Barnes (1977), entre outros, que negam que a ciência esteja imune a uma explicação social. Concomitantemente, há uma idéia tradicional de objetividade, expressa em Popper (1979) e Lakatos (1978), que refuta as injunções sociológicas na investigação e a explicação do conteúdo e da natureza do conhecimento científico, posto que seus pontos de vista têm constituído um ataque cético ao estatuto epistemológico inerente ao conhecimento.

De fato, segundo Palácios (1994:175-195), a maior parte dos opositores da sociologia contemporânea concentra suas objeções no princípio de causalidade. As disciplinas que tradicionalmente investigam a cognição humana refutam a relevância de variantes sociais na determinação do conteúdo das teorias científicas e vêem uma ameaça na sociologia de perspectiva causal.

A idéia de ciência como um complexo autônomo e de explicações neutras tem raízes na tradição da história da ciência, da filosofia e da própria sociologia da ciência. Nessa visão, os méritos de uma teoria independem de classe, raça, sexo e outras características de grupos, e, conseqüentemente, o 
desenvolvimento e a avaliação da ciência não estão sujeitos a uma explicação social (Chalmers, 1994). Para Palácios (1994), foi na intersecção dessas fronteiras que a sociologia da ciência foi constituída sem ter propriamente como objeto o conhecimento científico, preservando a filosofia da ciência como monopólio dos estudos relacionados a esse objeto.

Ele aponta a década de 70 como um momento em que a sociologia da ciência propôs uma ruptura com a tradição funcionalista desse campo, reivindicando como objeto de domínio de investigação o conhecimento como tal. Vale ressaltar que essa visão aproxima-se da abordagem de Chalmers (1994), quando assinala a recuperação dos clássicos Durkheim e Mannheim na formalização dessa ruptura, apresentada de modo sistematizado por Bloor, no livro Knowledge and Social Imagery, publicado em 1976.

Quanto a isso, Chalmers (1994) argumenta que não é o estatuto nãocognitivo da sociologia contemporânea que está em questão, mas os aspectos cognitivos sobre os quais pretende legislar. Informa ainda que, segundo Bloor (1982:283), as leis científicas adquirem estabilidade, não por razões internas da ciência, mas "devido à sua pressuposta utilidade para os propósitos de justificação, legitimação e persuasão social” (Chalmers, 1994:109). Já os tradicionalistas, defensores da ciência autônoma, se dispõem a considerar as causas sociais invocadas apenas quando se trata de explicar a boa ou a má ciência, versão também defendida por Chalmers, quando diz que certos gêneros de explicação sociológica do conteúdo cognitivo da ciência não têm cabimento. Trata-se de explicar o conteúdo cognitivo da ciência competente, em relação à meta preestabelecida e à característica da atividade, sob a premissa de que, se tacitamente se concorda com o mecanismo de percepção utilizado para a explicação desse conteúdo, não há razão para recorrer a nenhuma explicação especial, a fim de esclarecer por que as pessoas vêem o que estão vendo.

Por um lado, para Chalmers, os tradicionais estão corretos quando insistem que os méritos de uma teoria devem ser avaliados independentemente da psicologia, da classe social e de outras características externas (contudo, o argumento da indeterminação dá atenção insuficiente ao desenvolvimento da ciência). Por outro, ele considera que a passagem da indeterminação das teorias pelas evidências para o modelo de causalidade operado por Bloor (1982) e outros sociólogos da mesma tendência é apressada e acaba por fazer concessões aos tradicionalistas. 
É com base nessa crítica que Chalmers (1994) postula uma nova sociologia orientada pela história, assinalando que uma forma de construir o argumento sociológico é explicar o conhecimento científico por meio de uma história de como esse conhecimento foi elaborado. Nessa visão, o estudo da forma como uma teoria foi proposta exige uma resposta histórica (contexto da descoberta), ao passo que a forma pela qual a teoria é justificada como conhecimento satisfatório é outra espécie de questão que impõe uma resposta epistemológica (contexto da justificação), o que implica perpassar pelos textos produzidos pelos cientistas para trazer à tona as questões significativas que envolvem os seus componentes cognitivos. Nesse aspecto, a análise se volta para a coerência interna da teoria, mediante a recomposição de uma história interna da atividade científica.

Em verdade, para Palácios (1994), o modelo que se opõe à perspectiva causal defende a possibilidade e a validade de uma reconstrução racional da história da ciência que pode não coincidir com a história empírica, mas seria capaz de dar conta do desenvolvimento do conhecimento como tal.

Na perspectiva apontada por Chalmers (1994), fica visível, portanto, uma base teórica pela qual a educação alimentar pode ser analisada à luz da sua gênese, de modo a explicar como se constituiu o seu objeto e de que modo ele foi tratado na produção do paradigma proposto, o que remete ao contexto da sua descoberta. Outra opção é estender o estudo da educação alimentar para além do processo da sua gênese e constituição, em direção à análise da coerência interna do conhecimento produzido, levando em consideração a meta estabelecida pelos intelectuais fundadores desse campo. Isso implica perpassar pelas suas obras e recuperar as questões significativas que devem orientar a análise da coerência interna dos conceitos construídos.

Tal empreendimento se resume na preservação da distinção entre a descoberta científica como um fato em si e os processos mediante os quais ela vem a ser reconhecida publicamente como conhecimento satisfatório. Com esse empreendimento, objetiva-se separar os processos mentais tidos como determinantes fundamentais de uma descoberta e os processos sociais que incidem sobre o uso e a apreciação pública da inovação científica (Palácios, 1994).

Nesse aspecto, vale ressaltar que, em Chalmers (1994), não se encontram os elementos metodológicos que auxiliem a definição de um quadro referencial de análise da educação alimentar, nem no contexto de sua descoberta, nem no contexto de sua justificação. Além disso, o objetivo da 
pesquisa em foco não consiste na comprovação da coerência interna stricto sensu dos conceitos definidores da educação alimentar, suas provas objetivas e suas construções lógicas, mas, sim, na reconstituição do processo que a produziu, - que leva a considerar não ser possível cortar os laços com a história.

O conhecimento, como prática histórica, assume diversos sentidos, o que remete à crítica dialética das principais contribuições metodológicas desenvolvidas no campo da história da ciência, à luz da ciência da história, evitando a negação de abordagens importantes para a construção do quadro referencial de análise do processo de constituição da educação alimentar.

A tradição historiográfica do campo da história da ciência brasileira foi analisada por Motoyama \& Ferri (1978-1980). Projetando uma opção metodológica de estudo sobre a gênese e a constituição desse campo, estes operaram tanto com uma periodização peculiar ao processo, como com a caracterização de obras cujas tendências marcaram a trajetória do seu desenvolvimento. Nessa abordagem, os primórdios da história da ciência no Brasil correspondem aos primeiros estudos referentes ao fim do século passado até 1940 , caracterizados pelo tom comemorativo e de caráter narrativo sem rigor metodológico. 'Dialogando' com o livro A Cultura Brasileira, de Fernando Azevedo, publicado em 1943, Motoyama \& Ferri (1978-1980) assinalam que os estudos históricos da ciência se voltaram para análises de maior consistência metodológica, na perspectiva de explicar a atividade científica em sua globalidade como processo. Para eles, no entanto, Azevedo deixou de estabelecer as mediações entre o cultural e o econômico, persistindo numa exposição descritiva da atividade científica, lacuna que procurou superar na obra As Ciências no Brasil, em que aprofunda as circunstâncias sobre as quais o pensamento científico foi-se estabelecendo entre nós.

Nessa obra, Azevedo (s/d) destaca os dois surtos industriais (19141920 e 1939-1945) e a conseqüente expansão e diferenciação da vida urbana, decorrentes dos processos da industrialização e do deslocamento das populações. Os progressos tecnológicos no domínio da produção, dos transportes e das comunicações suscitaram a divisão do trabalho, a diferenciação e a mobilização social, assim como realçaram o valor da especialização e cooperação, sem as quais seria impossivel tornar o saber produtivo. Foi assim que tomou impulso o desenvolvimento das ciências físicas, naturais e humanas. Numa fase de renovação da cultura, que se ampliava e se diversificava, integrando aos seus elementos tradicionais as contribuições da ciência em transformação, desenvolveram-se a biologia e a fisiologia 
experimental, a sociologia, a antropologia e a psicologia, e se renovaram, no espírito e nos métodos, a geografia e a história. Assim, Azevedo produziu um quadro de grandes planos para descrever como nasceu e se desenvolveu, em nossa vida intelectual, o pensamento científico, e sob que circunstâncias lentamente se iniciou a sua organização. Reafirmando, portanto, nessa obra, a perspectiva de renovação cultural, o autor aprimorou a noção de cultura nacional por uma caracterização de sucessivos eventos culturais que, numa progressão linear e dualista, constituíram novas frentes de renovação (inclusive as diversas vertentes científicas) para o ajustamento aos novos tempos.

O plano de estudo assim concebido por Azevedo (s/d), como processo em angulação histórico-cultural, não obstante a sua importância para a história da ciência, auxilia muito mais uma reconstituição linear e narrativa do processo de gênese e constituição da educação alimentar, sem, no entanto, explicar as mediações entre essa vertente da produção cultural e as demais instâncias da cultura global em fase de renovação. Além disso, ao exprimir a função integradora e adaptativa desse processo, harmonizando posições divergentes num enfoque dualista da cultura, minimizando possíveis resistências culturais e disputas entre esse modo de produção cultural e as diversas formas de expressão de saberes e práticas em formação e desenvolvimento, esse procedimento contribuiria certamente para a enunciação de elementos justificadores da constituição desse campo, entre os diversos já instituídos. Depreende-se, da visão de Azevedo, que a configuração do pensamento científico, em seus primórdios, se deu em decorrência de uma revolução técnico-científica, na qual se instaurava a ciência como força fundamental, inaugurando uma nova era de progresso e racionalidade na evolução da cultura brasileira, cujos nexos explicadores desse dinamismo absorveram apenas os lineamentos gerais. Tal perspectiva prescinde, assim, de uma configuração metodológica que considere elementos de continuidade/ descontinuidade no processo de constituição da educação alimentar e que explicite, a partir dos problemas, enfoques e temas instauradores desse campo, os pretendidos nexos socioculturais e sua regularidade histórica. ${ }^{4}$

É, pois, no âmbito das tendências teórico-epistemológicas da ciência da história que se pode situar o estudo da gênese e a constituição da educação alimentar. Certamente, não é objetivo deste trabalho aprofundar a discussão de tais tendências, mas destacar que Schaff (1995), ao proceder a uma revisão

4 A este respeito, ver BENCHIMOL \& TEIXEIRA (1993); BRITO (1995); TEIXEIRA (1995); RIBEIRO (1993); e
YIDA (1993). 
crítica da matéria, opõe a história à crônica e coloca o papel da explicação na história. Contrariamente à crônica, essa revela os fenômenos de que fala. A explicação está contida, por definição, na noção de história. Saber o porquê dos fatos e a maneira pela qual esse saber foi adquirido - é nisso que consiste a explicação.

Nessa abordagem, a objetividade do conhecimento histórico é focalizada em todos os aspectos subjetivos que envolvem o proceder explicativo. As causas e leis constituem a base explicativa da análise histórica, o que demanda a realização de uma escolha, a começar pelo problema que se quer estudar, ou seja, pelo sistema de referência no qual se situa o fato histórico. É a teoria ou a hipótese que orienta a escolha do fato histórico entre os acontecimentos históricos, bem como a seleção dos materiais históricos, que constituem o fato determinado. $O$ pesquisador tem parte ativa na formulação da hipótese relativa ao passado, nas investigações, na verificação etc.

Para Schaff (1995), quando se fala de um fato histórico, trata-se, com toda a evidência, não apenas da objetividade do acontecimento como um fato histórico, mas, ainda, de um acontecimento qualificado, na medida em que, por causa da incidência sobre outros acontecimentos e, portanto, sobre o curso da história, reconhecemos a sua importância, que o qualifica como fato histórico passível de estudo no âmbito da ciência da história. Assim, o fato histórico é, por um lado, um fragmento da história acontecida, da realidade objetiva, e, por outro, o produto da interação específica do sujeito e do objeto como em todos os outros casos do proceder cognitivo. Que elementos caracterizam, então, o processo de gênese e constituição da educação alimentar como fato histórico? Tal questão remete à identificação dos sujeitos cognoscentes e do objeto construído, bem como da hipótese orientadora do processo de produção do conhecimento instituidor desse campo e sua incidência sobre outros acontecimentos históricos. Como afirma Schaff:

(...) se o historiador tem por fim explicar os acontecimentos históricos (senão, não seria a história), é preciso que se refira às leis mais diversas que, em domínios variados da realidade, estabelecem as regularidades na vida dos indivíduos e das sociedades. É apenas nesta condição que pode ser praticada a explicação causal dos acontecimentos determinados pelo recurso aos acontecimentos passados e presentes. (Schaff, 1955: 252)

Acresce a esta advertência a distinção feita pelo autor entre a explicação causal e a explicação genética, pois esta última, embora não se prenda a uma simples sucessão de fatos, mas a uma série de causas e efeitos, isolando apenas as condições necessárias, sem as condições suficientes, reduz o estudo a uma explicação probabilista. 
No contexto da explicação causal, a explicação finalista é não somente condição necessária, mas também suficiente para a compreensão da natureza e da objetividade do conhecimento histórico (Schaff, 1995). Explicar o processo de gênese e constituição da educação alimentar equivale a responder por que esse conhecimento se produziu. Isso remete à análise das causas que permearam a produção do conhecimento instituidor do campo, como também à análise do fim a que se destinava, de modo a responder à questão: com que objetivo o conhecimento foi produzido? Nesse proceder, por um lado, está implícita a necessidade da explicação que repõe os fundadores do campo, não como donos absolutos de seu sentido, pois eles representam um diálogo com outros enfoques, conceitos, temas e autores, e encontram-se, assim, inscritos nas fronteiras de outros campos científicos em processo de expansão e desenvolvimento; por outro lado, está implícita a necessidade de explicitação do(s) seu(s) destinatário(s). Conforme assinala Schaff:

Esta possibilidade e esta necessidade de apelar para a explicação finalista, sem perigo de cair no misticismo e no espiritualismo (inevitáveis, pelo contrário, se considerando o teologismo como o modo universal de explicação aplicável à realidade), estão na origem de uma das principais diferenças entre as ciências sociais e as exatas da natureza. (Schaff, 1995:256)

A despeito da notável contribuição desse autor para a definição de um quadro referencial de análise no âmbito da pesquisa em foco, prescinde-se, em sua obra, da explicação da questão das regularidades na produção do conhecimento, no que se refere aos elementos definidores de possíveis continuidades/descontinuidades no tempo, também se deixando vago, para o pesquisador, o próprio enfoque da periodização como elemento empírico da pesquisa e fator de inteligibilidade das mudanças significativas nesse processo.

Nesse aspecto, a abordagem de Le Goff (1994) é esclarecedora e complementar, quando assinala que a obra histórica não é uma obra de arte como as outras, o discurso histórico tem a sua especificidade. Para ele, a história é uma ciência, não do complexo, mas do específico, e, como todas as ciências, deve generalizar e explicar. Isso significa dizer que a aspiração a uma história total torna-se possível por meio de objetos globalizantes, construídos pelo pesquisador. Com isso, ele repõe para discussão duas noções na perspectiva histórica: a do sentido da história e a das leis da história. É nesse ponto que o enfoque de Le Goff (1994) difere de Schaff (1995), ao advertir que Marx não formulou leis gerais da história, mas conceitualizou o processo histórico, unificando teoria e prática revolucionárias. Assim, 
(...) o trabalho histórico tem por fim tornar inteligivel o processo histórico e (...) esta inteligibilidade conduz ao reconhecimento da 'regularidade' na evolução histórica (...) estas regularidades devem ser reconhecidas primeiro no interior de cada série estudada pelo historiador, que a torna inteligivel, descobrindo nela uma lógica, um sistema, termo que prefiro à intriga, pois ele insiste no caráter objetivo da operação histórica (...) o caráter científico da história reside tanto na valorização das diferenças como das semelhanças, enquanto que as ciências da natureza procuram eliminar as diferenças. (Le Goff, 1994:44-45)

Ao se voltar para a história contemporânea, o mencionado autor rememora a fundação da revista Annales, em 1929, como marco de renovação desse campo, indicando como questão central a refutação de uma história idealista guiada pela visão de um progresso linear que interpreta o passado com os valores do presente.

Segundo Burke (1992), a revista Annales foi idealizada e fundada em 1929, por Lucien Febvre e Marc Bloch, com base em três idéias fundamentais: substituir a tradicional narrativa dos conteúdos por uma história-problema; abranger a história de todas as atividades humanas e não apenas a história política; e viabilizar as duas primeiras idéias por uma colaboração com outras disciplinas, tais como a geografia, a sociologia, a psicologia, a economia, a lingüística, a antropologia social, entre outras. Burke, ao reconstituir e interpretar a história dos Annales, em termos da existência de três gerações de intelectuais situadas no âmbito desse movimento, no percurso de mais de 60 anos, conclui que a mais importante contribuição do grupo dos Annales foi, de fato, a ampliação do território da história a diversas áreas, contemplando aspectos do comportamento humano e de grupos sociais até então negligenciados pelos historiadores tradicionais.

Quanto a isso, Le Goff encontra em Francis Jacob a proposição de uma história que dá conta das condições materiais, sociais e mentais da sua produção e que individualiza, em toda a sua complexidade, as etapas do saber. As 'condições históricas' são definidas como o dar forma cognitiva à história concreta, um conhecimento da coerência científica; no entanto, não se trata, com isso, de invocar uma causalidade histórica pura, mas de recusar a validade de qualquer explicação e de toda prática que negligencie essas condições históricas (Le Goff, 1994).

Tal abordagem reivindica a necessidade do saber histórico em toda a ação científica, o que significa estender os elementos metodológicos e técnicos da ciência da história a todos os ramos das ciências, inclusive às biológicas, resguardando a especificidade de cada de cada uma delas. A aspiração da história à totalidade está em adquirir formas diferentes, podendo o fato histórico 
ser construído com uma realidade geográfica ou um conceito. A nova história tem, em primeiro lugar, objetivos de alargamento e aprofundamento da história científica, o que não significa o desprezo da investigação das causas por uma ligação ao princípio de indeterminação, mas a preservação de horizontes históricos do passado por outros meios. Nesta perspectiva, o documento corresponde a um acontecimento da história vivida e memorizada ou da história científica como produto de uma construção que compromete o sentido histórico das sociedades, bem como a validade de uma verdade histórica e o fundamento do trabalho histórico.

Outra característica importante desta visão de Le Goff (1994) se refere à continuidade/descontinuidade no processo histórico que se expressa no tempo. Isso põe o pesquisador em sintonia com o tempo, que, de diversas formas, apresenta-se como condição histórica, e, como tal, deve corresponder aos quadros referenciais de explicação cronológica à duração do vivido. Além disso, para que a datação se torne historicamente inteligível, deve ser acompanhada de outro procedimento necessário da duração - a periodização. A par de tais orientações, esta perspectiva vincula a história à memória como "elemento essencial do que se costuma chamar 'identidade', individual ou coletiva, cuja busca é uma das atividades fundamentais dos indivíduos e das sociedades de hoje, na febre e na angústia" (Le Goff, 1994:476).

Se a abordagem de Schaff (1995) permite situar o processo de gênese e constituição da educação alimentar como fato histórico pelas características já expostas, a perspectiva traçada por Le Goff (1994) possibilita analisá-lo historicamente em sua especificidade por uma ampla gama de registros de memória, de modo a desvendar os mecanismos da sua constituição. Vale assinalar que, embora seja passível de reconstituição o modo como se constrói um mito (a exemplo de Josué de Castro) na constituição da educação alimentar, verse-á que esse processo só pode ser compreendido à luz de uma memória coletiva, haja vista a existência de um conjunto de obras sobre alimentação e nutrição produzidas por um grupo de intelectuais, fato que orienta a construção de outro quadro explicativo.

A existência de explicadores da situação alimentar e nutricional brasileira, nos primórdios da instituição da educação alimentar, leva à configuração da datação na qual se desenvolveu esse processo, bem como a uma periodização plausível que permita mostrar como a produção pioneira desta modalidade de conhecimento se modificou no tempo, realçando internamente possíveis aproximações e diferenças entre os autores quanto aos problemas, enfoques e temas produzidos. Como argumenta Le Goff (1994:47): 
A periodização, como a própria história, é um processo empírico, delineado pelo historiador. Acrescentaria apenas que não há história imóvel e que a história também não é a pura mudança, mas sim o estudo das mudanças significativas. A periodização é o principal instrumento de inteligibilidade das mudanças significativas.

Com isso, a análise não somente estará voltada para a configuração do objeto desse campo e para o modo como foi tratado no conjunto da produção intelectual, mas também estará destacando os elementos de continuidade/descontinuidade, considerando uma dada periodização como fator de inteligibilidade de mudanças e as possíveis mediações entre essa produção e os diversos domínios da realidade, priorizando, assim, a explicação do modo como o referido campo foi proposto.

Em síntese, o traço fundamental da proposição de um paradigma na configuração de um novo campo aparece no reconhecimento preciso e operatório do objeto, esquema abstrato e virtual, cujas propriedades e leis a ciência em questão procurará posteriormente determinar. Isso leva, necessariamente, à caracterização de elementos de descontinuidade na história da ciência, como fenômeno de mutação no processo de conhecimento que levou à configuração do novo paradigma, fato que não ocorre ao mesmo tempo nos diferentes domínios do saber e depende também do estado das sociedades e da natureza conceitual do saber (Gilles-Gaston, 1994). Isso significa dizer que o reconhecimento preciso e operatório do objeto, na constituição da educação alimentar, não se rege por um acréscimo linear de idéias e fatos que se revela por um método de análise e soma, para com isso formar uma representação da realidade como agregado de coisas, processos e fatos. A substância desse fato histórico se revela nos elementos de descontinuidade externa que indicam ruptura, uma refundição global que marca oposição em relação a múltiplos pseudoparadigmas (saberes dispersos, isolados etc.) na constituição de um paradigma único que define esse novo campo, distinto, em suas características de subparadigmas posteriores desenvolvidos à luz da sua evolução, sem que sejam alteradas as condições determinantes da sua cientificidade. Assim, não há por que procurar elementos de descontinuidade interna no processo de constituição da educação alimentar, mas destacar as aproximações e diferenças entre os intelectuais em torno do reconhecimento do seu objeto e os deslocamentos operados nos enfoques e temas produzidos como arranjos internos e reordenações conceituais dos elementos definidores da base cognitiva desse campo. Com isso, fica patente também que somente ao final desse processo se exprimirá um conceito de 
identidade coletiva, que indicará o estatuto do grupo fundador do campo em apreço, fato que inviabilizará a definição a priori das características desse grupo. Nessa perspectiva, o estudo em foco indica o momento decisivo da gênese e constituição da educação alimentar mediante o esboço de uma periodização plausível e da análise dos traços norteadores da produção do conhecimento instaurador desse campo.

Oportunamente, a publicação Histórico do Nutricionista no Brasil (1991), da Associação Brasileira de Nutrição, auxiliou na delimitação do período a ser pesquisado, bem como na identificação dos nomes dos intelectuais envolvidos com a produção do conhecimento instaurador do campo da educação alimentar. Considerando que esta entidade indica a criação do Serviço de Alimentação da Previdência Social (SAPS), em 1940, como evento significativo e concomitante à criação dos primeiros cursos superiores de nutricionistas, nos anos de 1939 a 1946, pôde-se delimitar o período de 1930 a 1946 como parâmetro norteador do rastreamento do conjunto da produção especializada sobre alimentação e nutrição dos intelectuais envolvidos com esses dois eventos, os quais perfizeram um total de 19: Hélion Póvoa, Gilberto Freyre, G. H. de Paula Souza, Franklin de Moura Campos, Alexandre Moscoso, Thalino Botelho, Peregrino Júnior, Castro Barreto, Cleto Seabra Veloso, Dutra de Oliveira, Gilberto Vilela, Ruy Coutinho, Messias do Carmo, Josué de Castro, Sálvio de Mendonça, Souza Lopes, Ulhôa Cintra, Dante Costa e Rubens de Siqueira.

O procedimento de rastreamento do conjunto da produção especializada desses intelectuais envolveu a eleição de três acervos: Biblioteca Nacional, no Rio de Janeiro; Biblioteca da Escola Nacional de Saúde Pública da FIocruz, no Rio de Janeiro; e Biblioteca da Faculdade de Saúde Pública da Universidade de São Paulo (USP), em São Paulo. É fato conhecido que a Biblioteca Nacional (RJ) tem por atribuição a catalogação e guarda da produção nacional. Esse processo, contudo, não é seguido à risca, como foi constatado durante a pesquisa, o que justifica a eleição dos demais acervos em foco, como forma de assegurar a representatividade do material empírico da pesquisa e, além disso, facilitar o acesso ao mesmo. Como acervos circunscritos a dois grandes centros de ensino e pesquisa representativos no campo da saúde pública no País, a Biblioteca da Escola Nacional de Saúde Pública da Fiocruz (RJ) e a Biblioteca da Faculdade de Saúde Pública da USP (SP) conservam títulos que não se encontram na Biblioteca Nacional. 
A seleção do livro como material empírico se deu com base nos seguintes critérios:

- por se constituir no meio de divulgação que reunia, na época, condições privilegiadas para a análise de um conjunto orgânico de idéias; $e$

- o resultado do levantamento da produção sobre alimentação e nutrição indicou, de partida, a supremacia do livro como recurso adotado pelos intelectuais para a divulgação das suas produções, pois o periódico especializado ainda não era realidade no interior do campo da ciência da nutrição que se formava.

De fato, o primeiro periódico especializado foi editado em maio de 1944, 'intitulado' Arquivos Brasileiros de Nutrição, como publicação do Serviço Técnico da Alimentação Nacional (STAN), criado em 1942. Quanto a isso, a referida publicação tinha "como primeiro objetivo contribuir com a difusão de conhecimentos seguros da ciência da nutrição para a formação desse corpo de nutricionistas, especializados em quaisquer dos diferentes setores da matéria. Seu segundo objetivo é dar um conhecimento mais efetivo e mais amplo dos resultados dos trabalhos realizados no Brasil no campo da nutrição (Castro, 1944).

Isso também corrobora o uso do livro como material empírico de análise neste estudo e esclarece, de alguma forma a preferência dos intelectuais por esse instrumento na publicação de um sistema de idéias que se pretendia inovador no meio científico-cultural vigente, na época em que constituíram a educação alimentar.

Em tempo, a literatura aponta a década de 30 como um marco na organização e desenvolvimento do mercado editorial brasileiro, com impactos significativos na publicação do livro, que se acentuou nas décadas posteriores. Há concordância entre Andrade (1978) e Pontes (1989:359-409) quanto à expansão pela qual passava o mercado de bens culturais. Até a década de 20 , editar era tarefa difícil, operacionalizada por um número restrito de imigrantes. Nos anos 30, as edições passaram a ser viabilizadas por um número maior de pessoas que implantaram importantes editoras, sobretudo nos pólos urbanos de maior dinamismo econômico, como Rio de Janeiro, São Paulo, Belo Horizonte e Porto Alegre. Segundo Hallwell (1985:337), o crescimento na edição de livros foi marcante nesse período. E acresce: "As cifras para São Paulo sugerem uma taxa de crescimento na produção de livros entre 1930 a 1936, de mais de 600\%".

Como também assinala Miceli (1979), as instâncias de produção de bens culturais tendiam a se concentrar na Região Centro-Sul: em 1937, os 
estados de Minas Gerais, São Paulo e a capital do Rio de Janeiro detinham $54 \%$ das gráficas, dos quais São Paulo dispunha, unicamente, de $32 \%$. Tendência semelhante foi verificada no setor editorial, concentrando-se em três estados (São Paulo, Rio de Janeiro e Rio Grande do Sul), que reuniam $61 \%$ das editoras. As seis maiores editoras detinham $36 \%$ dos lançamentos no período de 1938 a 1943. É digno de nota que, neste período, do total de livros publicados (9.122) em distintos gêneros da produção cultural, 439 foram da área de medicina, perfazendo 2,5\% do total dos lançamentos das seis maiores editoras (Companhia Editora Nacional/Civilização Brasileira - SP/RJ -, Editora Globo - Porto Alegre -, Editora José Olympio - RJ -, Editora Irmãos Pongetti RJ -, Editora Francisco Alves - RJ - e Editora Melhoramentos - SP) e 5\% do conjunto das editoras. Disso se depreende a posição que já ocupavam no cenário os livros atinentes à área da saúde, da qual emergia a produção intelectual sobre a alimentação e nutrição. Nesse aspecto, distintos espaços editoriais foram utilizados pelos intelectuais, pois a maior parte $(77,31 \%)$ dos livros sobre alimentação e nutrição foi publicada no Rio de Janeiro, 17,01\% em São Paulo, 4,86\% em Porto Alegre, 0,24\% no México, 0,24\% em Recife e 0,24\% em Roma, por diversas editoras, entre outras: Editora Nacional, Civilização Brasileira, O Cruzeiro, Melhoramentos, Scientífica Brasileira, Flores \& Mano, Zélio Valverde etc. Outros livros (embora em menor quantidade) foram publicados por instituições estatais ligadas à saúde pública, ao Ministério da Agricultura etc.

Assim, a expansão do mercado do livro no âmbito da produção cultural global se deu em meio a importantes transformações operadas nos modos de produção e difusão culturais, que certamente afetaram a própria característica da produção intelectual nos anos 30 e 40, contexto em que ocorria um certo afrouxamento dos laços da dependência cultural. Vale ressaltar que, transitando entre distintas esferas culturais em expansão, os intelectuais em foco ultrapassaram os estudos especializados sobre alimentação e nutrição, produzindo também no campo literário, publicando documentários, romances, entre outras obras em que retratavam diversos aspectos do cenário sociocultural brasileiro, configurando-se, portanto, como sujeitos exemplarmente situados no plano cultural global, e não restritos a suas especialidades profissionais.

O registro dessa produção teve como critério inicial o fichamento de todos os títulos referentes à produção especializada sobre alimentação $e$ nutrição disponiveis no fichário ou computador dos acervos pesquisados, a partir do nome dos autores, incluindo todas as edições, o nome da editora, local e ano de publicação. 
Disso resultou o fichamento de 41 títulos especializados sobre alimentação e nutrição publicados no período de 1930 a 1946, dos quais três não foram localizados nas estantes, restando 38 exemplares correspondentes a 36 livros, um folheto e uma publicação em forma de cartilha, que perfazem $63,2 \%$ do total de intelectuais pesquisados, não se verificando, nos acervos, qualquer publicação especializada de Gilberto Vilela, Castro Barreto, Souza Lopes, Ulhôa Cintra, G. H. de Paula Souza, Franklin de Moura Campos e Gilberto Freyre.

Mediante uma leitura panorâmica preliminar dos 38 exemplares sobre alimentação e nutrição, disponíveis nos acervos pesquisados, pôde-se constatar duas vertentes de produção: uma parte dos livros esteve voltada para a explicação da conexão entre a dimensão fisiológica da alimentação e da nutrição e as características da organização social, com ênfase nos aspectos socioeconômicos e culturais; outra parte esteve voltada para a abordagem de natureza mais restrita a determinados ângulos específicos da alimentação: vitaminologia, patologias da nutrição, hipervitaminoses etc. Com base em tais características, pôde-se privilegiar, como critério de seleção do material empírico de análise, a inclusão de 14 livros, um folheto e uma cartilha que visavam explicar a conexão entre a dimensão fisiológica e os aspectos socioeconômicos e culturais do fenômeno da alimentação e da nutrição, pois foi nesse campo de abrangência que se pôde situar o objeto de estudo em questão (ver Anexo 1). Não obstante a predominância do livro como material empírico, justifica-se a inclusão do folheto e da cartilha, dada a sua importância como recurso ilustrativo do modo como os intelectuais elegeram os materiais pedagógicos pelos quais materializaram, na prática, as suas idéias educativas junto à população e, em particular, junto à classe trabalhadora, destinatária, em última instância, dos novos princípios de racionalidade alimentar cientificamente construídos.

Esta primeira leitura do material selecionado mostrou que foi no período entre 1934 e 1946 que se iniciaram os estudos sistemáticos sobre a ciência da nutrição e no seu âmbito a educação alimentar. Para que esta datação (1934 a 1946) se tornasse inteligível, foi acrescido outro procedimento necessário da duração - a periodização - como instrumento de clarificação dos deslocamentos significativos ocorridos no percurso da gênese e constituição da educação alimentar. Com isso, justifica-se o desenvolvimento da análise em dois momentos: 
- o período de 1934 a 1939, caracterizado por uma produção intelectual voltada para a configuração das bases científicas da alimentação racional, na perspectiva da caracterização inicial do objeto e dos modelos explicativos da ciência da nutrição em formação, e, no seu âmbito, a educação alimentar; $e$

- o período de 1940 a 1946, caracterizado por uma produção centrada no processo de reordenação do conhecimento anteriormente produzido, na perspectiva da síntese e definição precisa dos marcos conceituais e disciplinares desse campo, procedendo ao reconhecimento operatório do seu objeto. Outra característica diz respeito ao reconhecimento interno do estatuto do grupo fundador pelo qual se afirmava uma identidade coletiva no processo de constituição e institucionalização também desse mesmo campo. Assim, o livro O Problema Alimentar Brasileiro, de Josué de Castro (1934), marca o início desse estudo, que se conclui com o livro Geografia da Fome (1946), do mesmo autor, como será visto adiante.

Quanto a isso, a amostra de livros apresentada inclui prioritariamente a primeira edição e, só na sua falta, a segunda edição, representando, assim, um fragmento da produção sobre alimentação e nutrição referente aos anos de 1934 a 1946, pois, evidentemente, esta atividade intelectual se estende aos anos posteriores. Além disso, as obras levantadas informam outras publicações dos autores no período, inclusive sob o título de educação alimentar, que não se encontram nos acervos pesquisados. 